\title{
Combination of optical and non-destructive mechanical techniques for the measurement of maturity in peach
}

\author{
A. Herrero-Langreo ${ }^{\mathrm{a}, *}$, E. Fernández-Ahumada ${ }^{\mathrm{b}}$, J.-M. Roger ${ }^{\mathrm{b}}$, B. Palagós ${ }^{\mathrm{b}}$, L. Lleó ${ }^{\mathrm{c}}$

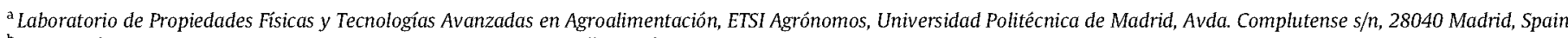 \\ ${ }^{\mathrm{b}}$ Cemagref, 361 rue Jean-François Breton, BP 5095, 34196 Montpellier Cedex 5, France \\ ${ }^{c}$ Departamento de Ciencia y Tecnologías Aplicadas a la Ingeniería Técnica Agrícola, EUTT Agrícolas, 28040 Madrid, Spain
}

Keywords:

Postharvest

Fruit

Peach

Maturity

Ripeness

Firmness

Multivariate analysis

\begin{abstract}
A B S T R A C T
Increasing consumer dissatisfaction related with lack of ripeness in peach has been repeatedly reported since 1990 to the present day. There is thus, a great interest in improving the assessment of peach maturity, currently based on Magness Taylor firmness (destructive, highly variable, and time consuming) and colour (not reliable for highly coloured varieties). The present research studies as an alternative several non-destructive (ND) measurements, based on multispectral imaging, visible spectra, and low mass impact response. Their relationship with maturity, as well as the potential of their combination was studied. As a result, two rather independent $\left(R^{2}=0.3\right)$ groups of non-destructive measurements, chlorophyll related optical indexes and low mass impact (LMI) measurements, were identified. Optical measurements showed the best behaviour for assessing maturity at harvest, while LMI measurements reflected handling incidences, showing a promising potential to be used to control transport and postharvest handling.
\end{abstract}

\section{Introduction}

Some of the most frequent consumer complaints about peach and nectarine cultivars are the hardness of the fruit and the lack of flavour (Bruhn, 1991; Crisosto et al., 2006; Della Cara, 2005; Iglesias and Echeverría, 2009). These problems are generally caused by fruit being harvested at immature stages, in order to avoid product wastage and to allow for long distance shipment. Furthermore, surveys carried out in France reported that $80 \%$ of consumers were dissatisfied (Clareton, 2000), pointing out the need and importance of improving the current control of peach quality.

Peach ripeness can be measured instrumentally by destructive or non-destructive techniques. Among destructive methods, Magness-Taylor penetrometry, proposed by Magness and Taylor (1925) as a measurement of flesh firmness; flesh colour; the determination of soluble solids content and tritratable acidity are the most extended peach ripeness references (Crisosto, 1994; Slaughter et al., 2006; Valero et al., 2007).

As an alternative, in recent years there has been an increasing interest in the development of non-destructive (ND) techniques which allow quick, efficient and systematic fruit quality assessment (Abbott, 1999; De Ketelaere et al., 2006; García-Ramos et al., 2005). In addition, ND techniques involve important advantages for performing on-line measurements, which are able to seg- regate the undesirable, or the outstanding individual fruit, instead of relying on sampling for biological products with large variability. ND techniques are as well, a valuable tool for monitoring fruit quality, allowing the repeated measurements of individual fruit over time.

Regarding ND techniques, in early research, ground colour (flesh colour or skin colour not locally affected by isolation or other effects) was reported to be a better at harvest indicator of quality after ripening than flesh firmness (Delwiche and Baumgardner, 1983). A colour grade scale based on $a^{*}$ colour coordinate (green-red) was proposed by Delwiche and Baumgardner (1983) as a maturity index and adopted by the South California Peach Board. More recently, in a study on 'Calanda' peaches (a yellow skin, uniformly coloured variety) $a^{*}$ CIELab coordinate was found to be a good maturity indicator, changing linearly during maturation (Ferrer et al., 2005).

However, the use of ground colour as maturity index in high coloured red skin cultivars as 'Richlady' has reported to be problematic by several authors (Crisosto, 1994; Tijskens et al., 2007; Ziosi et al., 2008), due to red blush colouration masking the ground colour. As discussed by Zude-Sasse et al. (2002), spectral measurements can be more specifically related to single pigments linked to fruit maturation, especially chlorophyll, which has a distinct maximum absorption peak at $680 \mathrm{~nm}$.

Ruiz-Altisent et al. (2006) observed that reflectance at $680 \mathrm{~nm}$ was inversely related to firmness for several yellow and red skin 
peach cultivars including 'Richlady'. Similar results were observed by Lu et al. (2006): backscattered light at $677 \mathrm{~nm}$ was related to chlorophyll content and gave the highest correlation with firmness of the peach flesh. Delwiche et al. (1987) used the reflectance ratio $R_{670} / R_{800}$ for sorting yellow clingstone peach ripeness, and Lleó et al. (2009) applied this index in multispectral imaging, developing a classification procedure which was able to identify four peach ripeness classes presenting significant differences in firmness reference measurements. Ziosi et al. (2008) defined an index based on this same principle, in absorbance terms: Index of Absorbance Difference at two wavelengths, 670 and $720 \mathrm{~nm}\left(I_{\mathrm{AD}}=A_{670}-A_{720}\right)$ which allowed the differentiation of two maturity classes of 'Fayette' (yellow skin) peaches. In a recent work, Lleó et al. (2011) proposed two other indexes: Ind $1=\left(R_{700}+R_{640}\right)-2 * R_{680}$ and Ind $2=R_{680} /\left(R_{640}+R_{700}\right)$; and compared them with previous indexes applied to red skin peach varieties (Ind $3=R_{670} / R_{800}$ and $\left.I_{\mathrm{AD}}\right)$, using hyperspectral imaging. Ind2 was the preferred index for assessing ripeness. It showed better discrimination between ripening stages and no influence of the effect of the curvature of the fruit on the index value.

With regard to other regions of the spectra, according to Merzlyak et al. (2003), the maximum absorption of carotenoids in the visible spectra occurs at $486 \mathrm{~nm}$. In turn, in the region from 400 to $550 \mathrm{~nm}$ combines chlorophyll and carotenoids absorption and from 530 to $550 \mathrm{~nm}$, occurs the maximum anthocyanins' absorption. Gitelson et al. (2002) and Merzlyak et al. (2003) proposed that to measure carotenoid content, reciprocal reflectance (1/reflectance) related to chlorophyll content should be subtracted from the reciprocal of reflectance on this spectral region combining chlorophyll and carotenoids absorption, and then divided by a reference (Reflectance at $800 \mathrm{~nm}$ ) for normalization.

Commercially, the most important criteria used, as described by Slaughter et al. (2006) with regard to peach processing in California, are flesh colour for distinguishing immature from mature fruit, and flesh firmness for discriminating overripe fruit and suitability for processing. Likewise, the combination of non-destructive (ND) measurements related with chlorophyll degradation (spectral indexes) and softening (impact measurements) could be considered for peach maturity and ripeness assessment.

Accordingly, the objectives of the present research are: (1) to explore the relationship between ND measurements (impact and optical), and (2) to test the potential of the combination of both kinds of techniques to assess peach maturity.

All optical indexes tested by Lleó et al. (2011) on hyperspectral imaging are considered in the presented research, computed from local spectrophotometer measurements (taken from a single point in the fruit), as well as variables extracted from multispectral imaging and low mass impact measurements.

\section{Materials and methods}

\subsection{Fruit samples}

Peaches were hand-harvested from an orchard in Murcia (Spain). Fruit measurements were taken along two seasons (2006 and 2007) from red skin melting firm peaches (cultivar 'Richlady').

As fruit quality properties can vary significantly depending on the region of the fruit assessed, two areas, divided by the suture of the fruit, were identified and differentiated. Each fruit side was measured independently and single fruit sides were considered as sample units $(n)$ for the whole work in order to be able to compare fruit properties regardless of the variability within fruits. The average of three measurements per fruit side was taken for mechanical measurements (MTF and impact) and one measurement per fruit side for the optical (spectral measurements and multispectral image).
In 2006, three dates were sampled: commercial harvest date $(\mathrm{CH} ; n=120)$, one week in advance $(\mathrm{CH}-1 ; n=120)$ and one week after $(\mathrm{CH}+1 ; n=80$ ). In 2007 (season 2 ), in order to obtain a wider ripeness range, five harvest dates were considered: commercial harvest date $(\mathrm{CH})$, one week later $(\mathrm{CH}+1)$ and one, two and three weeks in advance $(\mathrm{CH}-1, \mathrm{CH}-2, \mathrm{CH}-3)$, taking 40 measurements for each harvest date. In overall, 320 peach sides $(n)$ were measured in 2006 (season 1) and 200 in 2007 (season 2).

\subsection{Instrumental methods}

Two kinds of optical techniques were applied:

Spectral indexes obtained from multispectral images (Lleó et al., 2009): Images of reflectance at $680 \mathrm{~nm}$ (wavelength of maximum chlorophyll absorption) were normalized (divided pixel by pixel) by reflectance images at $800 \mathrm{~nm}$, obtaining $R_{680} / R_{800}$ images as a result. The mode of each $R_{680} / R_{800}$ image histogram was computed and used as a continuous variable ('rir'), expected to be related with maturity and firmness.

Optical indexes computed from spectral local measurements recorded with Minolta spectrophotometer (Lleó et al., 2011; Merzlyak et al., 2003). Indexes tested to study peach ripeness on hyperspectral images by Lleó et al. (2011), were evaluated (Chlorophyll related indexes: Ind1, Ind2, Ind $\left.3, I_{\mathrm{AD}}\right)$. All these indexes are conceived to reflect changes in the chlorophyll content. They are centred on the spectral region of maximum chlorophyll absorbance and apply different corrections on the spectra in order to minimize spectral distortions as multiplicative or additive effects. Finally, as observed by Ramina et al. (2008) carotenoids increase during fruit maturation and stabilize or decrease during ripening. Therefore, another index ('Icarot'), related with carotenoids and based on the reflectance interactions between pigments discussed by Merzlyak et al. (2003), were as well considered. According to Merzlyak et al. (2003), reflectance at $480 \mathrm{~nm}$ was chosen as a term sensitive to carotenoids (and chlorophyll); reflectance at $680 \mathrm{~nm}$ as a term related to chlorophyll, and reflectance at $700 \mathrm{~nm}$ (maximum wavelength measured by the Minolta CM-508i) as a reference, resulting in the following index:

$I_{\text {carot }}=R_{700}\left(1 / R_{480}-1 / R_{680}\right)$

In addition, low mass impact and Magness-Taylor Firmness (MTF) were measured for every sample.

MTF measures flesh failure properties (i.e. peak force to penetrate the flesh through a cylindrical penetrometer probe) as described by Magness (1925).

Low mass impact measurements were acquired by our ownprototype LPF-Lateral Impact Sensor. The technique consists of impacting the sample with a spherical low-mass of $10 \mathrm{~g}$, and registering the deceleration process with a piezoelectric accelerometer. These measurements are non-destructive and are based on the observation of elastic properties rather than tissue failure properties in order to reflect flesh softening along ripening. Further details are given by García-Ramos et al. (2005). Several parameters extracted from low mass impact measurements were included in this analysis: impact firmness (Imp) measured as maximum impact acceleration $\left(\mathrm{m} / \mathrm{s}^{2}\right)$; impact hardness, measured as maximum impact acceleration by time, Imp2 $\left(\mathrm{M} \mathrm{m} / \mathrm{s}^{3}\right)$ and impact maximum deformation, Imp3 $(\mu \mathrm{m})$.

Table 1 gathers the variables considered in the analysis, their nomenclature and significance with regard to maturity.

\subsection{Relationship between non-destructive measurements and maturity}

Peach maturity was referenced by the date of harvest, considering the maturation period of the fruits on the tree as a measure- 
Table 1

Variables used in the analysis, their signification and nomenclature.

\begin{tabular}{|c|c|c|c|c|}
\hline Non-destructive (ND) measurements & & & & $\begin{array}{l}\text { Destructive (D) measurement } \\
\text { (illustrative) }\end{array}$ \\
\hline \multirow[t]{5}{*}{ Chlorophyll optical indexes } & Ind $1^{*}$ & $\left(R_{700}+R_{640}\right)-2^{*} R_{680}$ Lleó et al. (2011) & $\begin{array}{l}\uparrow \text { Index value } \\
\uparrow \text { Expected chlorophyll content } \\
\downarrow \text { Expected maturity }\end{array}$ & $\begin{array}{l}\text { MTF }(\mathrm{N}) \uparrow \text { value; } \uparrow \text { firmness } \\
\text { lexpected maturity }\end{array}$ \\
\hline & $\operatorname{lnd} 2^{*}$ & $R_{680} /\left(R_{640}+R_{700}\right)$ Lleó et al. (2011) & $\begin{array}{l}\uparrow \text { Index value } \\
\downarrow \text { Expected chlorophyll content } \\
\uparrow \text { Expected maturity }\end{array}$ & \\
\hline & $\operatorname{lnd} 3^{*}$ & $\begin{array}{l}R_{680} / R_{700} \text { Delwiche et al. (1987), Lleó } \\
\text { et al. }(2009)\end{array}$ & $\begin{array}{l}\uparrow \text { Index value } \\
\downarrow \text { Expected chlorophyll content } \\
\uparrow \text { Expected maturity }\end{array}$ & \\
\hline & $I_{\mathrm{AD}}$ & $\log 10\left(R_{700} / R_{670}\right.$ Ziosi et al. (2008) & $\begin{array}{l}\uparrow \text { Index value } \\
\uparrow \text { Expected chlorophyll content } \\
\downarrow \text { Expected maturity }\end{array}$ & \\
\hline & rir & $\begin{array}{l}\text { Mode } R_{680} / R_{800} \text { of the fruit image Lleó } \\
\text { et al. (2011) }\end{array}$ & $\begin{array}{l}\uparrow \text { Index value } \\
\downarrow \text { Expected chlorophyll content } \\
\uparrow \text { Expected maturity }\end{array}$ & \\
\hline Carotenoids optical index & Icarot ${ }^{*}$ & $\begin{array}{l}R_{700} / R_{480}-R_{700} / R_{680} \text { Merzlyak et al. } \\
(2003)\end{array}$ & $\begin{array}{l}\uparrow \text { Index value } \\
\uparrow \text { Expected carotenoids content } \\
\uparrow \text { Expected maturity }\end{array}$ & \\
\hline \multirow[t]{4}{*}{$\begin{array}{l}\text { Low mass impact measurements (LMI } \\
\text { measurements) }\end{array}$} & $\operatorname{Imp}$ & Maximum impact acceleration $\left(\mathrm{m} / \mathrm{s}^{2}\right)$ & $\begin{array}{l}\uparrow \text { Index value } \\
\uparrow \text { Firmness } \\
\downarrow \text { Expected maturity }\end{array}$ & \\
\hline & $\operatorname{Imp} 2$ & Impact hardness (imp/imp3) $\left(\mathrm{M} \mathrm{m} / \mathrm{s}^{3}\right)$ & $\begin{array}{l}\uparrow \text { Index value } \\
\uparrow \text { Firmness } \\
\downarrow \text { Expected maturity }\end{array}$ & \\
\hline & $\operatorname{lmp} 3$ & Time for maximum acceleration ( $\mu s)$ & $\begin{array}{l}\uparrow \text { Index value } \downarrow \text { firmness } \uparrow \text { expected } \\
\text { maturity }\end{array}$ & \\
\hline & Imp4 & Maximum deformation $(\mu \mathrm{m})$ & $\begin{array}{l}\uparrow \text { Index value } \uparrow \text { firmness } \downarrow \\
\text { expected maturity }\end{array}$ & \\
\hline
\end{tabular}

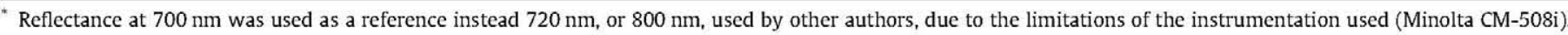

ment of maturity. Nevertheless, as it has been reported that peach trees produce a staggered maturation. They tend to mature from top to bottom and from periphery to interior, presenting a sequential maturation for the same tree. Consequently, peach trees generally require to be harvested several times for each season (Crisosto and Valero, 2008).

This phenomenon produces high variability in fruit maturity from the same tree and harvest date. In the experimental design peach fruits were sampled from all over the tree for all dates, producing a high variability in the maturity of peaches from the same harvest date. Therefore, the average of fruits from a certain harvest date was expected to be more mature as time went on, but an important overlap in maturity was expected between harvest dates. Consequently, average values for each harvest date are used as a reference of the overall state of maturity for each harvest date.

\subsubsection{Principal component analysis (PCA): factors interpretation}

The original dataset ( $n$ observations on $p$ original variables) was decomposed into a new set of data ( $n$ observations, or 'scores', on $k$ uncorrelated variables, or 'PCA factors').

The projections of the original feature variables onto the new variables are considered as 'factor coordinates' of the original variables.

PCA factors were computed from season 1 data using optical and low mass impact (LMI) measurements as original variables. The original dataset was autoscaled before computing the PCA.

The relationship between PCA factors and the original variables were computed and plotted. The main directions grouping the projection of the $p$ original variables in the PCA space were analyzed and interpreted. Further on, and according to the PCA interpretation, meaningful directions were used to define new axes in the PCA.

\subsubsection{Definition of new axis in the $P C A$}

New axes were defined as a combination of the two groups of ND variables considered (LMI and optical). The equation of the new axes as a function of the PCA factors was computed as a linear fit of each group of variables centred in the geometrical centre of the PCA space (the centre for every factor would be 0 , as the original dataset was centred and reduced).

Each new axis was defined by its coordinates in the PCA space. These coordinates were computed geometrically as the projection of the new axis, which was considered as a new variable, into F1 and $\mathrm{F} 2$.

The equation of each new axis was computed from the PCA "correlation circle" (Fig. 1) as a linear combination of two PCA fac-

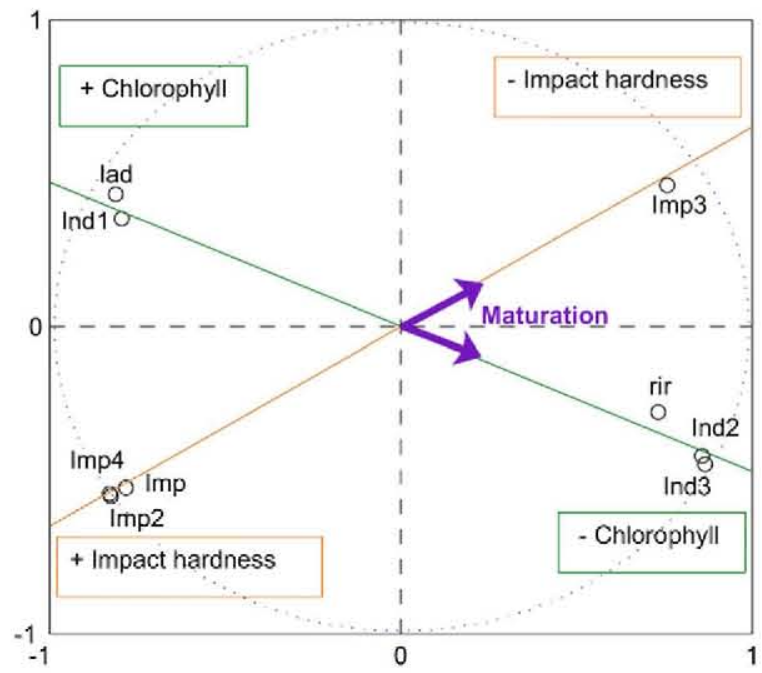

Fig. 1. Scheme of the coordinates of a variable as a function of a PCA factor. Projection of the original feature variables onto PCA factors 1 (F1) and 2 (F2). Optical (Opt) and Mechanical axis $(\mathrm{Mec})$ are represented and interpreted. Blue arrows indicate the direction of the expected effect of maturation on the axis (according to Table 1) $N=311$ from season 1 . (For interpretation of the references to colour in this figure legend, the reader is referred to the web version of this article.). 
tors (Eqs. (10) and (11)). From these equations the value of $\mu$, the slope or gradient of the equations, was obtained. Further on, the coordinates of the new axis into PCA factors were computed from the following system:

$$
\begin{aligned}
& \mu=\operatorname{Coord} 2 / \text { Coord } 1 \\
& 1=\operatorname{Coord}^{2}+\operatorname{Coord}^{2}
\end{aligned}
$$

Where Coord1 is the coordinate (value) of the axis of the first Factor, Coord2 of the second factor.

As a result of the system of equations, the value of the coordinates of each axis were obtained. The new axes $\left(A x_{j}\right)$ were defined as the following vector:

$A x_{j}=\left[\begin{array}{l}\text { Coord } 1 \\ \text { Coord } 2\end{array}\right]$

\subsubsection{Relationship between axes}

Square correlation $\left(r^{2}\right)$ between two axes $\left(A x_{1}\right.$ and $A x_{2}$ as defined in Eq. (3)) can be obtained geometrically as the square cosine of the angle between both vectors (Otto, 2007). The cosine of the angle was computed from the inner product according to the following equation:

$A x_{1}^{T} \cdot A x_{2}=\operatorname{Coord} 1_{A x_{1}} \operatorname{Coord}_{A x_{2}}+\operatorname{Coord} 2_{A x 1} \operatorname{Coord} 2_{A x 2}$

(Superscripted $T$ means the transposition of the matrix). Geometrically, the inner product can as well be expressed as:

$A x_{1}^{T} \cdot A x_{2}=\cos \alpha|A x-1|\left|A x_{2}\right|$

Where $\left|A x_{1}\right|$ and $\left|A x_{2}\right|$ are the modules of the vectors considered. Given the definition of the axis coordinates in Eq. (2), both modules would equal 1 (this is, the distance from the axis coordinates ( $\mathrm{CO}$ ord1 and Coord2) to the centre of the PCA)

Then,

$\left(A x_{1}^{T} \cdot A x-2\right)^{2}=(\cos \alpha)^{2}=r^{2}$

\subsubsection{Axes relationship with maturity: PCA scores computation and projection onto the new axes}

Autoscaled data from both seasons were projected into the PCA space (scores computation) and onto the new axes (scores projection onto the new axes). Data from season 1, used to compute PCA factors, were centred and reduced using its own mean and standard deviation. Data from season 2, projected as complementary data to the PCA, was centred and reduced using season 1 mean and standard deviation.

The distribution and mean values of each harvest date for these new variables were used to study their relationship with maturity.

The projection of the scores on the new axis (Proy) was computed as a change of coordinates as follows:

$\operatorname{Proy}_{(n x N a x)}=X_{(n x p)} V_{(p x k)} U_{(k x N a x)}$

where PCA scores are computed as the product of the $n$ observations on the $p$ original variables, $(X)$, and the "loadings", or projections of the $p$ original variables onto the $k$ PCA factors $(V) . U$ is the matrix containing the coordinates of each new axis on the PCA factors, and Nax the number of new axis to compute.

Considering each axis $\left(A x_{1}\right.$ to $\left.A x_{N a x}\right)$ defined by its coordinates as expressed in Eq. (3), $U$ can be written as:

$U=\left[\begin{array}{llll}A x_{1} & A x_{2} & \ldots & A x_{\text {Nax }}\end{array}\right]$

As an example, considering two axes and three factors:
$U=\left[\begin{array}{ll}\operatorname{Coord}_{A x_{1}} & \operatorname{Coord}_{A x_{2}} \\ \operatorname{Coord}_{A x_{1}} & \operatorname{Coord}_{A x_{2}} \\ \operatorname{Coord}_{A x_{1}} & \operatorname{Coord}_{A x_{2}}\end{array}\right]$

\section{Results and discussion}

\subsection{Outliers detection}

It was detected that for nine of the samples, LMI features started being recorded before the mass impacted the fruit. Thus, parameters related with deformation or time ( $\operatorname{mp2}$ and $\operatorname{lmp} 3$ ) were not correctly registered. These samples were excluded from further analysis. As a result 311 observations (320-9) were used in the season 1 data.

\subsection{Relationship between non-destructive measurements and maturity}

\subsubsection{Principal components analysis (PCA): factors interpretation}

As shown in Table 2, 95\% of the explained variance of the original dataset was gathered by the first four factors in the PCA. All variables except Icarot showed to be best correlated with first factor (gathering $61 \%$ of explained variance). Ind 2 and Ind 3 presented the highest square correlation with this factor $\left(r^{2}=0.73-0.75\right)$; while Imp2 and Imp4 were the best explained mechanical variables $\left(r^{2}=0.68-0.69\right)$.

Chlorophyll optical indexes based on spectrophotometer measurements (Ind1, Ind2, Ind3 and $I_{\mathrm{AD}}$ ) and LMI measurements (imp to imp4) were mainly explained by factors 1 and 2 . As observed from their contributions to the variance (Ctr.) shown in Table $2,86 \%$ and $94 \%$ of the explained variance of factor 1 and 2 , respectively was explained by these two groups of measurements. In addition, $80.4 \%$ of the PCA variance $(61.6 \%$ and $18.8 \%$, respectively) was explained by these first two factors. Factors 3 and 4 were mainly explained by Icarot ( 0.5 and 0.4 , respectively of the explained variance of the factor was explained by Icarot). In this regard, carotenoids content has been observed to increase throughout fruit maturation and decrease or stabilize at the end of the peach maturation process (Ferrer et al., 2005; Ramina et al., 2008 ). Its estimation through spectral measurements is greatly affected by interactions with other pigments (Merzlyak et al., 2003). Thus, the estimation of chlorophyll degradation through spectral indexes related with factors 1 and 2 was expected to be a more reliable indicator of fruit maturation than Icarot. Consequently, only factors 1 and 2 were considered for further analysis.

As pointed out by (Otto, 2007), information about the correlation of feature (original) variables can be deduced from the PCA variables plot (Fig. 1). The correlation of two features is described by the cosine of the angle between the variables vectors: the smaller the angle the higher is the correlation between features. If variables are closely correlated then only one of the correlated variables is generally studied. Consequently, increasing values on PCA factor 1 (F1) appeared related to lower chlorophyll contents (negative correlation with Ind 2 and Ind 3 and positive with Ind 1 and $I_{\mathrm{AD}}$ ) and lower values of impact hardness (negative correlation with imp2). Therefore, increasing values of F1 were associated with increasing maturity stages (see Table 2 about nomenclature and meaning of each variable regarding peach maturity stages).

In contrast, higher values of PCA factor 2 (F2) were associated with increasing chlorophyll contents and with decreasing impact hardness. Given that physiologically both chlorophyll content and impact hardness are expected to decrease during maturation, these results reflect the influence of some effect other than 
Table 2

Factor coordinates (Coord), absolute values of correlation $|r|$, and contributions to the variance (Ctr.) for by each original variable and factor on the PCA.

\begin{tabular}{|c|c|c|c|c|c|c|c|c|c|c|c|c|}
\hline & \multicolumn{3}{|c|}{ Factor 1 ( $61.6 \%$ of the variance) } & \multicolumn{3}{|c|}{ Factor 2 ( $18.8 \%$ of the variance) } & \multicolumn{3}{|c|}{ Factor 3 ( $9.51 \%$ of the variance) } & \multicolumn{3}{|c|}{ Factor $4(5.29 \%$ of the variance $)$} \\
\hline & Coord & $|r|$ & Ctr. & Coord & $|r|$ & Ctr. & Coord & $|r|$ & Ctr. & Coord & $|r|$ & Ctr. \\
\hline Ind1 & -0.80 & 0.79 & 0.10 & 0.35 & 0.35 & 0.07 & 0.36 & 0.36 & 0.14 & -0.30 & 0.30 & 0.17 \\
\hline Ind2 & 0.86 & 0.85 & 0.12 & -0.42 & 0.42 & 0.09 & -0.16 & 0.17 & 0.03 & 0.24 & 0.24 & 0.11 \\
\hline Ind3 & 0.87 & 0.87 & 0.12 & -0.45 & 0.45 & 0.11 & 0.18 & 0.17 & 0.03 & 0.08 & 0.10 & 0.01 \\
\hline $\mathrm{I}_{\mathrm{AD}}$ & -0.81 & 0.81 & 0.11 & 0.43 & 0.44 & 0.10 & -0.33 & 0.33 & 0.12 & 0.04 & 0.00 & 0.00 \\
\hline Rìr & 0.73 & 0.73 & 0.09 & -0.28 & 0.28 & 0.04 & 0.42 & 0.42 & 0.18 & -0.39 & 0.40 & 0.29 \\
\hline lcarot & 0.54 & 0.55 & 0.05 & -0.17 & 0.17 & 0.02 & -0.67 & 0.67 & 0.47 & -0.46 & 0.47 & 0.41 \\
\hline $\operatorname{lmp}$ & -0.78 & 0.78 & 0.10 & -0.53 & 0.53 & 0.15 & 0.08 & 0.10 & 0.01 & -0.02 & 0.00 & 0.00 \\
\hline $\operatorname{Imp} 2$ & -0.83 & 0.82 & 0.11 & -0.55 & 0.56 & 0.16 & 0.00 & 0.00 & 0.00 & -0.01 & 0.00 & 0.00 \\
\hline $\operatorname{Imp} 3$ & 0.76 & 0.76 & 0.09 & 0.46 & 0.46 & 0.11 & 0.14 & 0.14 & 0.02 & 0.00 & 0.00 & 0.00 \\
\hline Imp4 & -0.83 & 0.83 & 0.11 & -0.54 & 0.55 & 0.16 & -0.02 & 0.00 & 0.00 & -0.04 & 0.00 & 0.00 \\
\hline
\end{tabular}

maturity on PCA factor 2, for which fruit softening would not be related with chlorophyll loss (degradation).

\subsubsection{New axes on the PCA}

As plotted in Fig. 1, two main groups of variables, aggregated in two pertinent directions were found in factors 1 and 2:

\section{- An optical axis, related with spectral indexes and chlorophyll content. \\ - A mechanical axis related to LMI measurements.}

When considering the plane defined by factors 1 and 2, plotted in Fig. 1, these two groups of measurements showed $70 \%$ of complementation and $30 \%$ of dependency (the square cosine of the angle between both directions is 0.3 ). This result agrees with previous work (Ruiz-Altisent et al., 2006) which observed non-destructive (impact) firmness and reflectance at selected wavelengths to be complementary and related to the maturity of peach fruit, merging several peach varieties.

Accordingly to the greater importance of factor 1 to explain every variable, optical and mechanical axes were respectively $85 \%$ and $70 \%$ dependent on factor 1 .

Increasing values in the optical axis were linked to decreasing chlorophyll content, whereas increasing values in the mechanical axis were related to decreasing impact hardness (imp2). Both, the loss of impact hardness and of chlorophyll content were expected to be associated with increasing maturity stages. Therefore, those axes could be considered as a more pertinent object of study than PCA factors.

\subsubsection{Axes relationship with maturity: PCA scores computation and} projection onto the new axes

In order to test the ability of optical and mechanical axes to register maturity stages, season 1 population was projected on the new axes. Each axis was expressed as a function of PCA factors 1 and 2 , geometrically computing the slope, $\mu$, of each axis regarding PCA factors. As a result, optical axis was expressed as:

$F 2=-0.47 * F 1$

And mechanical axis as:

$F 2=0.65 * F 1$

As noted in point 2.3.2 optical (Opt1, Opt2) and mechanical axis coordinates (Mec1, Mec2) were obtained from the systems of Eqs. (1) and (2); making $\mu=-0.47$ for the optical axis and $\mu=0.65$ for the mechanical axis.

As a result, a matrix, $U$, as expressed in Eqs. (8) and (9) was defined containing the coordinates of each new axis as:

$U=\left[\begin{array}{ll}\text { Opt1 } & \text { Mec1 } \\ \text { Opt2 } & \text { Mec2 }\end{array}\right]=\left[\begin{array}{cc}0.90 & 0.84 \\ -0.42 & 0.55\end{array}\right]$
The values projected onto the new axis were obtained according to Eq. (9), where $X$ (autoscaled original dataset) and $V$ (loadings matrix for each factor and original variable, gathered in Table 2) had the following dimensions: $n=311$ (number of observations), $k=2$ (number of factors in the PCA), and $p=10$ (number of original variables) and Nax $=2$ (number of new axis to compute).

Considering each axis separately, as shown in Fig. 2, histograms of the scores projection onto the optical axis showed a bias to higher values for later harvest dates, increasing from pre-commercial $(\mathrm{CH}-1)$ to commercial $(\mathrm{CH})$ and finally to post-commercial $(\mathrm{CH}+1)$ harvest dates. In contrast, commercial and post-commercial harvest dates were not distinguished on the histograms of mechanical axis projections (Fig. 3). This result is also illustrated by Fig. 4, which plots the scores projected onto optical and mechanical axis for each harvest date.

Due to the staggered maturation of fruit in peach trees as pointed out in 2.3 , a wide dispersion of maturity was observed within the dates. Consequently, only mean values of the mechanical and optical axis for each harvest date (Fig. 5), were considered as references of maturity, assuming that fruits from earlier harvest dates would be, on average, more immature than those from later harvest dates.

Considering both axes simultaneously, it can be observed that the centre of gravity of the three harvest dates in first season appeared ordered along a convex curve. These observations could be explained by $\mathrm{CH}$ fruits being softer (i.e. higher values on the mechanical axis) than expected according to its chlorophyll content (registered by the optical axis). This interpretation would be supported by a handling incidence in $\mathrm{CH}$ population: prior its transport to Madrid it suffered five extra-hours of storage in sealed boxes.

It could be further interpreted that fruit samples evolved (probably more by respiration than by dehydration) during this period.

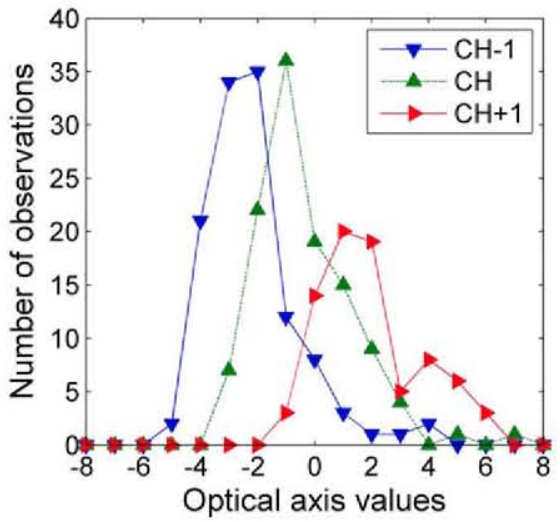

Fig. 2. Histograms of the projection of scores ( $n=311$ observations from season 1$)$ onto Optical axis for each harvest date. 


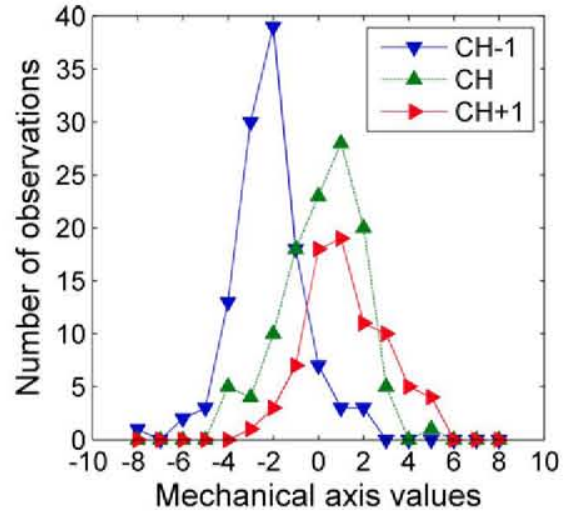

Fig. 3. Histograms of the projection of scores ( $n=311$ observations from season 1$)$ onto Mechanical axis for each harvest date.

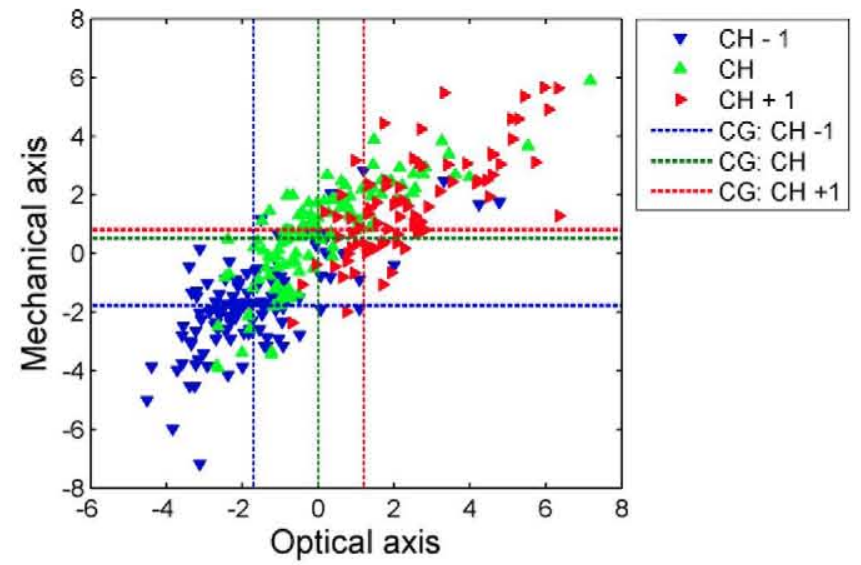

Fig. 4. Projection of scores ( $n=311$ observations from season 1 ) onto mechanical and optical axes categorized by harvest date. Mean values of each harvest date are represented as a solid point and each of its coordinates are projected on dotted lines of the corresponding colour for each harvest date.

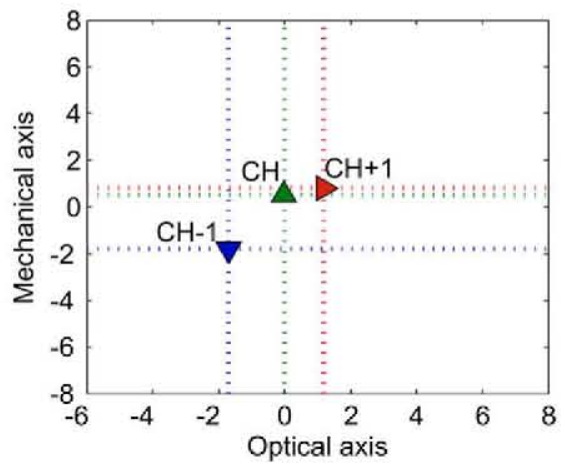

Fig. 5. Mean values for each harvest date of the projections of scores onto optical and mechanical axes. ( $n=311$ observations from season 1 ).

In order to test this interpretation a second PCA was computed including only SSC and weight, which are the main variables affected by these two physiological processes. Fig. 6 shows the relationship between these variables in a PCA space built for season 1 data $(n=311)$.

Factor 1 in the PCA would be related with processes for which SSC and mass would evolve in the same way (such as respiration, which reduces both SSC and mass). In contrast, factor 2 would be related to processes which produce mass and SSC to evolve in dif-

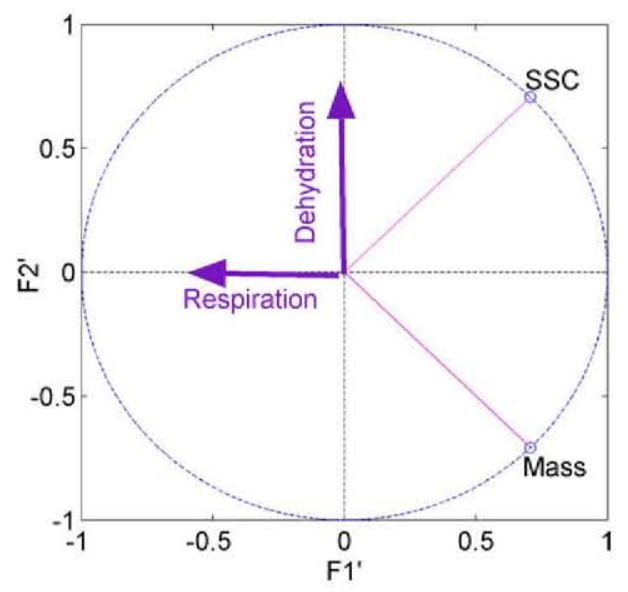

Fig. 6. Projection of SSC $\left({ }^{\circ} \mathrm{Brix}\right)$ and Mass (g) onto PCA factors 1 (F1', 64.7\% variance) and 2 (F2', 35.29\%). Season $1(n=311)$.

ferent directions (such as dehydration which induces mass decrease as well as SSC increase due to sugars concentration).

As observed in Fig. 7, pre-commercial $(\mathrm{CH}-1)$ and post-commercial harvest populations $(\mathrm{CH}+1)$ overlapped for both factors while commercial harvest $(\mathrm{CH})$ population were biased toward lower values of factor 1 . This result would imply lower mass and SSC values, suggesting a greater incidence of respiration processes in $\mathrm{CH}$ population.

As a conclusion, optical measurements were able to register harvest date in an unbiased but imprecise way, while mechanical axis was influenced by postharvest incidences as well as by the date of harvest. These results suggest a better ability of chlorophyll based optical indexes to register maturity stage and a good potential of impact measurements to control postharvest handling.

\subsubsection{Validation: projection of season 2 data}

Season 2 data were projected onto the optical and mechanical axes generated in season 1. In Fig. 8, the effect of harvest date on season 2 population is illustrated. Again, a high variability within harvest dates was observed, and mean values for each harvest date, plotted in Fig. 9, were used as a reference of maturity.

Three groups of harvest dates were correctly ordered by the optical axis:

- $\mathrm{CH}-3$ and $\mathrm{CH}-2$

$-\mathrm{CH}-1$ and $\mathrm{CH}$

$-\mathrm{CH}+1$

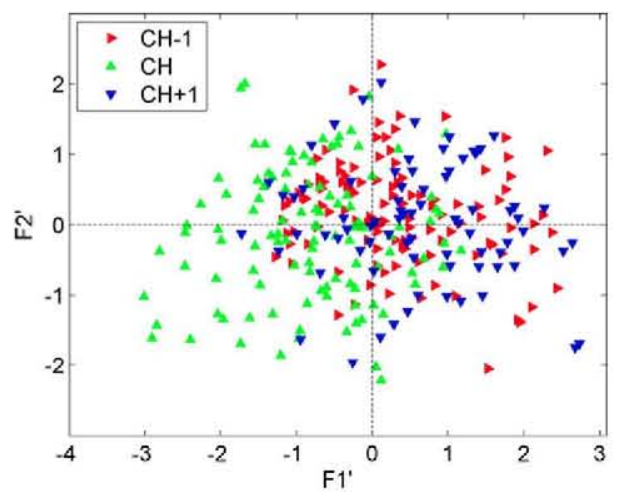

Fig. 7. PCA scores representation of SSC ( $\left.{ }^{\circ} \mathrm{Brix}\right)$ and mass (g) onto PCA factors, factor 1 in abscissas $\left(F 1^{\prime}\right)$ and factor $2\left(F 2^{\prime}\right)$ in ordinates, (Season $1, n=311$ ). 


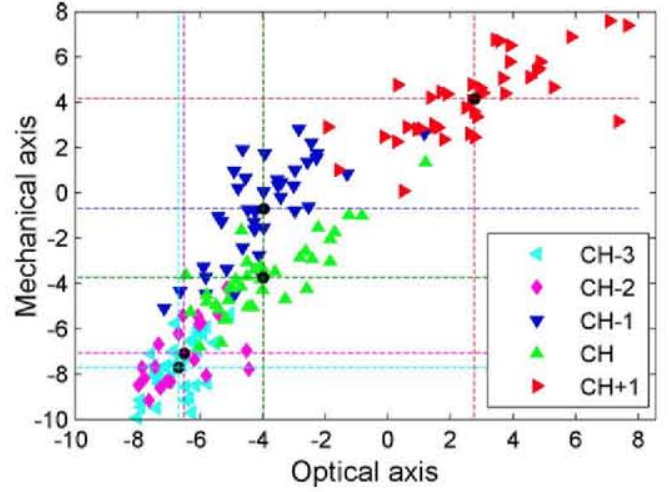

Fig. 8. Projection of PCA scores ( $n=200$ observations from season 2 ) mechanical and optical axes, categorized by harvest date. The mean values per harvest date are projected as dotted lines of the corresponding colour for each harvest date.

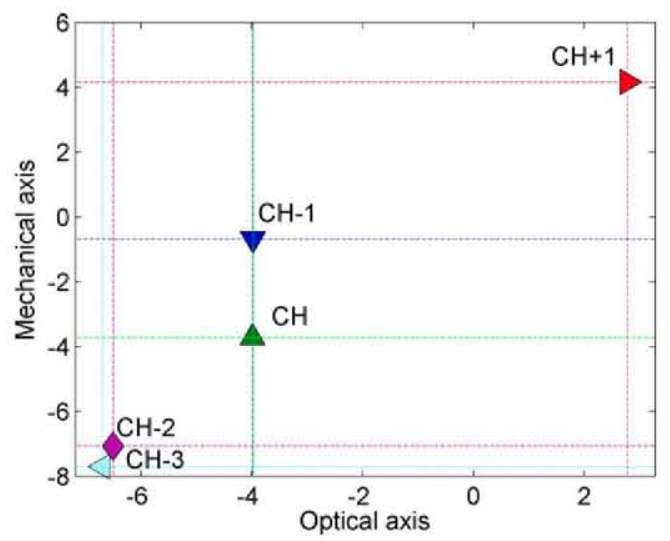

Fig. 9. Centres of gravity for each harvest date of the projections of scores onto optical and mechanical axes. ( $n=200$ observations from season 2).

In contrast, mean values of pre-commercial and commercial harvests were misplaced by mechanical axis, supporting optical chlorophyll indexes as a better reference of maturity.

Pre-commercial harvest $(\mathrm{CH}-1)$ from season 2 , presented unexpectedly high mechanical axis values which could not be explained in this work. Previous results in season 1 suggested an effect of handling conditions on LMI measurements, but a dedicated experiment would be needed to fully explain this effect.

\subsubsection{Analysis of seasonal variations}

Considering both seasons simultaneously, Table 3 gathers the mean values of the projection on the optical axis for each harvest date for seasons 1 and 2 . If optical indexes were considered as an indicator of maturity, it would be concluded that pre-commercial $(\mathrm{CH}-3, \mathrm{CH}-2$ and $\mathrm{CH}-1)$ and commercial $(\mathrm{CH})$ harvest dates from season 2 were less mature than any of the populations from season $1(\mathrm{CH}-1, \mathrm{CH}$, or $\mathrm{CH}+1)$ while post-commercial $(\mathrm{CH}+1)$

Table 3

Mean values of the scores projection on the optical axis for season $1(n=311)$ and season $2(n=200)$.

\begin{tabular}{lcl}
\hline & Season 1 & Season 2 \\
\hline $\mathrm{CH}-3$ & - & -6.7 \\
$\mathrm{CH}-2$ & - & -6.5 \\
$\mathrm{CH}-1$ & -1.7 & -4.0 \\
$\mathrm{CH}$ & -0.0 & -4.0 \\
$\mathrm{CH}+1$ & 1.2 & 2.8 \\
\hline
\end{tabular}

harvest from season 2 was the most mature population. This effect is as well illustrated in Fig. 10.

This maturity ordering agrees with MTF values for each harvest date. As observed in Tables 4 and 5 . As an average, pre-commercial $(\mathrm{CH}-3, \mathrm{CH}-2$ and $\mathrm{CH}-1)$ and commercial $(\mathrm{CH})$ harvest dates from season 2 were firmer (higher MTF) than any of the populations from season 1 , while post-commercial harvest $(\mathrm{CH}+1)$ from season 2 and season 1 presented similar MTF ranges.

Fig. 10 plots mean values on Mechanical and Optical axis for each harvest date and both seasons. Optical and Mechanical axis values remained unbiased, showing to be robust to seasonal differences.

Summing up, two groups of variables, optical and mechanical, were identified onto a PCA plane (first two factors), gathering most (80.4\%) of the variance. As the PCA space was built with data from the same variety and season, and all variables included in the analysis that had been referenced (Bassi and Monet, 2008; Cascales

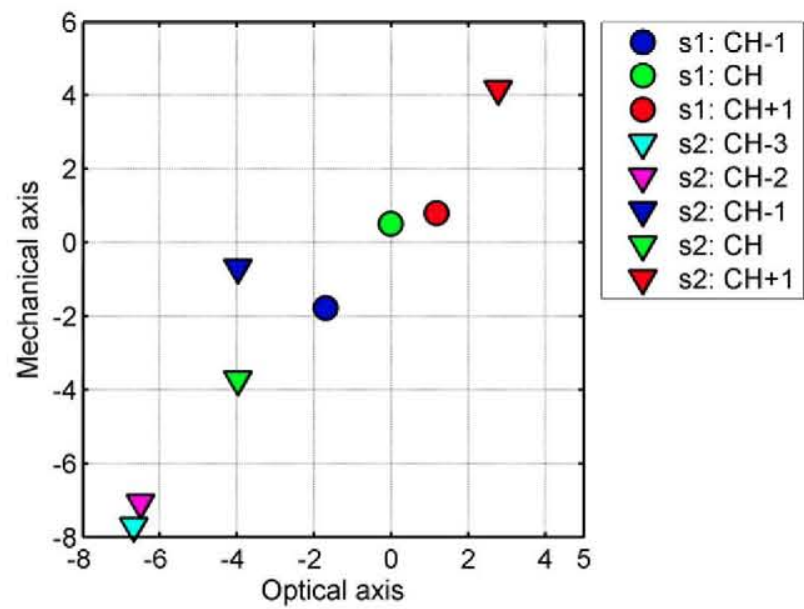

Fig. 10. Mean values for each harvest date of the projections of scores onto optical and mechanical axes ( $n=311$ from season 1, s1, $n=200$ observations from season 2, s2).

Table 4

Statistical properties of MTF measurements from season 1 categorized by harvest date.

\begin{tabular}{lrrlr}
\hline Season 1 & $\mathrm{CH}-1$ & $\mathrm{CH}$ & $\mathrm{CH}+1$ & Total \\
\hline$N$ & 119.0 & 114.0 & 78.0 & 311.0 \\
Mean & 53.5 & 47.3 & 34.8 & 46.5 \\
Variance & 56.0 & 41.5 & 39.9 & 100.3 \\
Median & 54.5 & 46.5 & 35.6 & 46.6 \\
Minimum & 24.5 & 30.5 & 20.5 & 20.5 \\
Maximum & 71.6 & 63.1 & 46.2 & 71.6 \\
1st Quartile & 48.8 & 42.3 & 29.7 & 40.2 \\
3rd Quartile & 58.1 & 51.9 & 39.1 & 54.5 \\
\hline
\end{tabular}

Table 5

Statistical properties of MTF measurements from season 2 categorized by harvest date.

\begin{tabular}{lrrlllr}
\hline Season 2 & $\mathrm{CH}-3$ & $\mathrm{CH}-2$ & $\mathrm{CH}-1$ & $\mathrm{CH}$ & $\mathrm{CH}+1$ & Total \\
\hline $\mathrm{N}$ & 40.0 & 40.0 & 40.0 & 40.0 & 40.0 & 200.0 \\
Mean & 114.9 & 83.0 & 65.1 & 58.5 & 36.8 & 71.6 \\
Variance & 126.2 & 60.7 & 43.7 & 33.8 & 51.3 & 749.4 \\
Median & 112.6 & 82.4 & 65.5 & 59.4 & 38.8 & 65.9 \\
Minimum & 92.9 & 71.1 & 51.6 & 43.5 & 24.0 & 24.0 \\
Maximum & 135.9 & 103.4 & 81.6 & 68.3 & 52.3 & 135.9 \\
1st Quartile & 107.4 & 76.9 & 60.5 & 55.3 & 31.0 & 53.4 \\
3rd Quartile & 123.0 & 89.7 & 69.6 & 63.0 & 41.0 & 89.7 \\
\hline
\end{tabular}


et al., 2005; Crisosto, 1994, 1996; Ramina et al., 2008; Ruiz-Altisent et al., 2006) as being related with maturity or ripening, it could be concluded that two groups of variables, optical and mechanical, were complementary and actually explaining variations in the maturity of the dataset. This conclusion agrees with previous work by Ruiz-Altisent et al. (2006), who used single wavelengths reflec tance, colour coordinates, MTF and LMI measurements on several groups of varieties. In the present work, only non-destructive measurements are considered for the assessment of maturity and reflectance indexes are used instead of single reflectance's or colour, according to the recommendations observed in recent works (Herold et al., 2005; Merzlyak et al., 2003; Xue and Yang, 2009; Ziosi et al., 2008; Zude, 2003). Two axes could be defined: Optical and Mechanical (ND). The independence between these two axes was quantified and suggested the effect of two rather independent (70\% independent) processes which would be related to maturity.

\section{Conclusions}

As a conclusion, two groups of non-destructive measurements, chlorophyll related optical indexes and low mass impact (LMI) measurements were successfully combined to assess peach maturity, using mean values of sequential harvest dates as a maturity reference. Optical measurements showed the best behaviour for assessing maturity at harvest, while LMI measurements reflected handling incidences (few extra-hours of shipping had an effect on LMI measurements), showing a promising potential to be used to control transport and postharvest handling. In further work the ability of non-destructive low mass impact measurements to monitor transport and post-harvest handling and incidences could be tested with a dedicated experimental design.

\section{Acknowledgements}

This work was carried out in the frame of TAGRALIA-CM program, ISAFRUIT-EU 6th FP IP and MULTIHORT projects. The authors wish to thank Dr. F. Riquelme from CEBAS-CESIC (Spain) for his help with the selection of samples.

\section{References}

Abbott, J.A., 1999. Quality measurement of fruits and vegetables. Postharvest Biology and Technology 15, 207-225.

Bassi, D., Monet, R., 2008. Botany and Taxonomy. In: Layne, D.R., Bassi, D. (Eds.), The Peach: Botany, Production and Uses. CAB International, Oxfordshire.

Bruhn, C.M., 1991. Consumer perceptions of quality: apricots, cantaloupes, peaches, pears, strawberries and tomatoes. Journal of Food Quality 14, 187-195.

Cascales, A.I., Costell, E., Romojaro, F., 2005. Effects of the Degree of Maturity on the Chemical Composition, Physical Characteristics and Sensory Attributes of Peach (Prumus persica) cv Caterin. Food Science and Technology International 11, 345352. doi: $10.1177 / 1082013205057943$.

Clareton, M., 2000. Peach and nectarine production in France. trends, consumption and perspectives, in Summaries Prunus breeders meeting. Empresa Brasileira de Pesquisa Agropecuária Clima Temperado Pelotas (RS), Brazil (pp. 83-91).

Crisosto, C.H., 1994. Stonefruit maturity indices: a descriptive review. Post-harvest news and information $5,64-68$.

Crisosto, C.H., 1996. Optimum procedures for ripening stone fruit. Management of Ripening Fruit. Postharvest Horticulture 9, 28-30.

Crisosto, C.H., Valero, C., 2008. Harvesting and postharvest handling of peaches for the fresh market. In: Layne, D.R., Bassi, D. (Eds.), The Peach: Botany, Production and Uses. $C A B$ International, Oxfordshire.
Crisosto, C.H., Crisosto, G.M., Echeverria, G., Puy, J., 2006. Segregation of peach and nectarine (Prumus persica (L.) Batsch) cultivars according to their organoleptic characteristics. Postharvest Biology and Technology 39, 10-18.

De Ketelaere, B., Howarth, M.S., Crezee, L., Lammertyn, J., Viaene, K., Bulens, I., De Baerdemaeker, J., 2006. Postharvest firmness changes as measured by acoustic and low mass impact devices: a comparison of techniques. Postharvest Biology and Technology 41, 275-284.

Della Cara, R., 2005. In calo ì consumi e l'export de pesche e nettatine italiane. Rivista di Frutticoltura 7-8, 19-20.

Delwiche, M., Baumgardner, R.A., 1983. Ground colour measurements of peach. Journal of American Society of Horticultural Science 108, 1016-1020.

Delwiche, M., Tang, S., Rumsey, J.W., 1987. Color and optical properties of clingstone peaches related to maturity. American Society of Agricultural Engineers 30, 1873-1879.

Ferrer, A., Remón, S., Negueruela, A.I., Oria, R., 2005. Changes during the ripening of the very late season Spanish peach cultivar Calanda: feasibility of using CIELAB coordinates as maturity indices. Scientia Horticulturae $105,435-446$.

García-Ramos, F.J., Valero, C., Homer, I., Ortiz-Cañavate, J., Ruiz-Altisent, M., 2005. Non-destructive firmness sensors: a review. Spanish Journal of Agricultural Research 3, 61-73.

Gitelson, A., Zur, Y., Chivkunova, O.B., Merzlyak, M.N., 2002. Assessing carotenoids content in plant leaves with reflectance spectroscopy. Photochemistry and photobiology $75,272-281$.

Herold, B., Truppel, I., Zude, M., Geyer, M., 2005. Spectral measurements on [']Elstar' apples during fruit development on the tree. Biosystems Engineering 91, 173182.

Iglesias, I., Echeverría, G., 2009. Differential effect of cultivar and harvest date on nectarine colour, quality and consumer acceptance. Scientia Horticulturae 120 , 41-50.

Lleó, L., Barreiro, P., Ruiz-Altisent, M., Herrero, A., 2009. Multispectral images of peach related to firmness and maturity at harvest. Journal of Food Engineering 93, 229-235.

Lleó, L., Roger, J.M., Herrero-Langreo, A., Diezma-Iglesias, B., Barreiro, P., 2011 Comparison of multispectral indexes extracted from hyperspectral images for the assessment of fruit ripening. Journal of Food Engineering 104, 612-620.

Lu, G., Huang, H., Zhang, D., 2006. Prediction of sweetpotato starch physiochemical quality and pasting properties using near-infrared reflectance spectroscopy. Food Chemistry 94, 632-639.

Magness J.R., Taylor, G.F., 1925. An improved type of pressure tester for the determination of fruit maturity. USDA Circular. Washington D.C.: USDA 350

Merzlyak, M.N., Solovchenko, A.E., Gitelson, A.A., 2003. Reflectance spectral features and non-destructive estimation of chlorophyll, carotenoid and anthocyanin content in apple fruit. Postharvest Biology and Technology 27, 197-211.

Otto, M., 2007. Chemometrics, statistics and computer application in analitical chemistry. Weinheim, Federal Republic of Germany.

Ramina, A., Tonutti, P., McGlasson, B., 2008. Ripening, nutrition, and postharvest physiology. In: Layne, D.R., Bassi, D. (Eds.), The Peach: Botany, Produciton and Uses. $\mathrm{CAB}$ International, Oxfordshire.

Ruiz-Altisent, M., Lleó, L., Riquelme, F., 2006. Instrumental quality assessment of peaches: fusion of optical and mechanical parameters. Journal of Food Engineering 74, 490-499.

Slaughter, D.C., Crisosto, C.H., Hasey, J.K., Thompson, J.F., 2006. Comparison of instrumental and manual inspection of clingstone peaches. Applied engineering in agriculture. American Society of Agricultural and Biological Engineers, 22.

Tijskens, L.M.M., Zerbini, P.E., Schouten, R.E., Vanoli, M., Jacob, S., Grassi, M., Cubeddu, R., Spinelli, L., Torricelli, A., 2007. Assessing harvest maturity in nectarines. Postharvest Biology and Technology 45, 204-213.

Valero, C., Crisosto, C.H., Slaughter, D., 2007. Relationship between nondestructive firmness measurements and commercially important ripening fruit stages for peaches, nectarines and plums. Postharvest Biology and Technology 44, 248253.

Xue, L., Yang, L., 2009. Deriving leaf chlorophyll content of green-leafy vegetables from hyperspectral reflectance. ISPRS-Journal of Photogrammetry and Remote Sensing 64, 97-106.

Ziosi, V., Noferini, M., Fiori, G., Tadiello, A., Trainotti, L, Casadoro, G., Costa, G., 2008 A new index based on vis spectroscopy to characterize the progression of ripening in peach fruit. Postharvest Biology and Technology 49, 319-329.

Zude-Sasse, M., Truppel, I., Herold, B., 2002. An approach to non-destructive apple fruit chlorophyll determination. Postharvest Biology and Technology 25, 123133

Zude, M., 2003. Comparison of indices and multivariate models to non-destructively predict the fruit chlorophyll by means of visible spectrometry in apple fruit. Analytica Chimica Acta 481, 119-126. 